\title{
A COMPARATIVE STUDY OF RISK FACTORS OF CARDIOVASCULAR DISEASES IN YOUNG ADULTS WITH FAMILY HISTORY OF HYPERTENSION/DIABETES MELLITUS
}

\author{
Muhammed Ashraf Kayakkal1, Geetha Paninjath Ayyappan², Pradeep Kumar Kotha Muttath ${ }^{3}$ \\ ${ }_{1}^{1}$ Associate Professor, Department of Biochemistry, Government Medical College, Kozhikode, Kerala, India. \\ ${ }^{2}$ Additional Professor, Department of Biochemistry, Government Medical College, Kozhikode, Kerala, India. \\ ${ }^{3}$ Scientific Assistant, Department of Biochemistry, Government Medical College, Kozhikode, Kerala, India.
}

\section{ABSTRACT}

\section{BACKGROUND}

Non-communicable chronic diseases viz. diabetes mellitus, obesity, hypertension, cardiovascular diseases are assuming importance among the adult population in both developed and developing countries. Hypertension, cardiovascular diseases, diabetes and obesity are closely interrelated. Among these, diabetes mellitus, hypertension, hypercholesterolemia etc. have strong hereditary component.

\section{MATERIALS AND METHODS}

In this study the risk factors of cardiovascular diseases was compared in 50 young adults with family history of hypertension/diabetes mellitus (Group 1) and 50 young adults without family history of hypertension/diabetes mellitus (Group 2). Physical and chemical parameters like systolic and diastolic blood pressure, body mass index (BMI), waist to hip ratio, fasting blood sugar (FBS) and fasting lipid profile (FLP) were evaluated.

\section{RESULTS}

Waist to hip ratio $(p$-value $=0.011)$, FBS $(p$-value $=0.018)$, total cholesterol $(p$-value $=0.046)$ and LDL cholesterol $(p$-value $=0.015)$ were significantly elevated in group 1 when compared to group 2.

\section{CONCLUSION}

Waist to hip ratio, fasting blood sugar, total cholesterol and LDL cholesterol were significantly increased in young adults with family history of diabetes or hypertension, compared to others without family history of diabetes or hypertension. This necessitates blood investigations in the younger age group and further follow up study to identify the risk of dyslipidaemia, diabetes mellitus, obesity and development of cardiovascular diseases in our population.

\section{KEY WORDS}

Diabetes Mellitus, Hypertension, Dyslipidaemia, Obesity, Cardiovascular Diseases, Young Adults.

HOW TO CITE THIS ARTICLE: Kayakkal MA, Ayyappan GP, Muttath PKK. A comparative study of risk factors of cardiovascular diseases in young adults with family history of hypertension/diabetes mellitus. J. Evolution Med. Dent. Sci. 2018;7(52):5492-5496, DOI: $10.14260 /$ jemds/2018/1215

\section{BACKGROUND}

Non-communicable chronic diseases viz. diabetes mellitus, obesity, hypertension, cardiovascular diseases are assuming importance among the adult population in both developed and developing countries.[1] Hypertension, cardiovascular diseases, diabetes and obesity are closely interrelated. Among these, diabetes mellitus, hypertension, hypercholesterolemia etc. have strong hereditary component.

Hypertension and diabetes mellitus account for about $40 \%$ of all coronary heart disease. Hypertension accelerates the atherosclerotic process, especially if hyperlipidaemia is also present. The relationship between habitual diet, blood cholesterol-lipoprotein levels and coronary heart disease are judged to be causal.[2]DM is a metabolic disease due to absolute or relative insulin deficiency.

'Financial or Other Competing Interest': None.

Submission 02-05-2018, Peer Review 15-11-2018,

Acceptance 22-11-2018, Published 24-12-2018.

Corresponding Author:

Geetha Paninjath Ayyappan,

Additional Professor,

Department of Biochemsitry,

Government Medical College,

Kozhikode, Kerala, India.

E-mail:drgeethapa10@gmail.com

DOI: $10.14260 /$ jemds/2018/1215

\section{(c) $(1)(5)$}

It is a common clinical condition affecting about $10 \%$ of the population. ${ }^{[3]}$ It is characterized by chronic hyperglycaemia with disturbances of carbohydrate, fat and protein metabolism. The effects of diabetes mellitus include long term damage, dysfunction and failure of various organs, especially the eyes, kidney, heart and blood vessels. ${ }^{[4]}$

The population in India has an increased susceptibility to diabetes.[5] Diabetes is listed among the five most important determinants of the cardiovascular disease epidemic in Asia.

Insulin resistance and/or hyperinsulinemia have suggested as being responsible for increased arterial pressure in patients with hypertension. This feature is now widely recognized as part of syndrome $\mathrm{X}$, or the metabolic syndrome, marked also by central obesity, dyslipidaemia (Especially elevated triglycerides) and high blood pressure. Insulin resistance is more common in patients with diabetes mellitus type 2 and in obesity.[5]

Hypertension is the commonest cardiovascular disease. It is the major risk factor for cardiovascular mortality, which accounts for $20-50 \%$ of all deaths. It is also one of the most common complex genetic disorders, with genetic heritability averaging to $30 \%$. Blood pressure levels are determined in part by genetic factors and inheritance is polygenic. Obesity is a risk factor for hypertension. The greater the weight gain, the greater the risk for high blood pressure. 
Hypertension is one of the major cause for myocardial infarction and congestive heart failure, cerebrovascular accidents and chronic kidney disease.[6] In non-diabetic populations, the risk of coronary heart disease (CHD) increases in continuous and graded fashion with increasing blood pressure.[7]

Obesity, diabetes mellitus, thyroid diseases, renal disorders, liver disorders, glycogen storage diseases, Cushing syndrome etc. are seen associated with dyslipidaemia. ${ }^{[8]}$ Even though plasma levels for lipid and apo protein were within the normal range, the increased frequency of LDL phenotype B confirms a greater risk of atherosclerosis development in children with diabetes mellitus. $[9,10]$

In these circumstances this study was conducted by assessing the major risk factors of cardiovascular diseases in the offspring of diabetic or hypertensive parents.

\section{MATERIALS AND METHODS}

\section{Study Design}

Cross sectional comparative study.

\section{Sample Size Calculation}

As per study by Gaziano JM et al, the SD of HDL was $11 \mathrm{mg} \%$. To detect an effective size of $7 \mathrm{mg} \%$ between the groups, the sample size required was estimated as 40 in each group.

\section{Sampling Method}

50 first year M.B.B.S. students of Govt. Medical College, Kozhikode with documented family history of diabetes or hypertension were taken as cases in the study. They were selected randomly by generating random numbers using WINPEPI software. Similarly 50 students of same batch without family history of diabetes or hypertension were taken as control using the same random method. For assessing the family history, disease status of father and mother only is considered.

\section{Inclusion Criteria}

Students in the age group of 18 - 25 years were selected for the study with documented family history of having or not having diabetes or hypertension were included in the study.

\section{Exclusion Criteria}

Subjects who were already diagnosed to have diabetes or hypertension and who failed to give informed written consent were excluded from the study.

\section{Study Duration}

The period of study was one year.

The Institutional Ethics Committee of Medical College, Kozhikode approved the study, and all study participants provided informed written consent.

\section{Study Methods}

The following physical and chemical parameters were evaluated in this study; Weight, Height, BMI, Waist Hip Ratio, Pulse rate, Blood Pressure (Systolic and Diastolic), Fasting Lipid Profile, Total Cholesterol, Triglyceride, HDL Cholesterol, LDL Cholesterol, VLDL Cholesterol and Fasting blood sugar. All biochemical parameters were estimated by using fully automated clinical chemistry analyser based on standard protocol. Adequate quality control was ensured by including both normal and abnormal commercial reference control serum in each batch.[11]

Total cholesterol estimation was done using the reagent set Autozyme cholesterol, based on enzymatic method using Cholesterol esterase, Cholesterol oxidase and Peroxidase. HDL Cholesterol estimated by using AutoZyme HDLCholesterol Precipitating Reagent.[12-14]

Triglyceride estimation was done by enzymatic GPO-POD Glycerol phosphate oxidase and Peroxidase (GPO-POD) method.[15]

VLDL cholesterol was estimated from the total amount of Triacyl glycerol (TAG). This estimation is based on the average ratio of TAG to cholesterol in VLDL, accepted by National Cholesterol Education Programme.

LDL cholesterol was estimated by indirect method and this method generally quantitate a so-called "broad-cut fraction" including not only the primary LDL species, but also VLDL.

\section{Statistical Analysis}

Data were coded and entered in excel data sheet. Analysis done by Epi-Info. Comparative study of socio-demographic and biochemical features of the subjects was done. Results are expressed as mean and standard deviation for quantitative variables and as frequency percentage for qualitative variables. The results were analysed statistically using chi square and T-test. The results were considered significant at the level of $\mathrm{P}<0.05$.

\section{RESULTS}

100 subjects of age group 18-25 years were included in the study. They were grouped into two - Group 1 include children of either mother or father diagnosed of having diabetes mellitus or hypertension or taking medicines for either. Group 2 subjects whose parents are not diagnosed of having diabetes or hypertension. There were 60 males and 40 females with mean age of 19.18 in both groups. Group wise details of demographic features are given in table 1-2. In group 1, $16 \%$ of subjects' mother have diabetes and $16 \%$ have hypertension, $62 \%$ of subjects' father have diabetes and $28 \%$ have hypertension.

\begin{tabular}{|c|c|c|c|}
\hline Sex & Group 1 & Group 2 & Total \\
\hline Male & 28 & 32 & 60 \\
\hline Female & 22 & 18 & 40 \\
\hline Total & $\mathbf{5 0}$ & $\mathbf{5 0}$ & $\mathbf{1 0 0}$ \\
\hline \multicolumn{2}{|r|}{ Table 1. Sex Distribution of Study Group } \\
\hline
\end{tabular}

\begin{tabular}{|c|c|c|c|c|c|c|c|c|c|c|c|c|}
\hline & 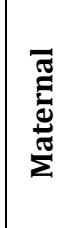 & 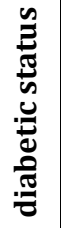 & 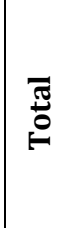 & 胥 & क & సేّ & & 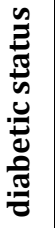 & 䒕 & 丞 & $\frac{n}{3}$ & 营 \\
\hline & Yes & No & Total & Yes & No & Total & Yes & No & Total & Yes & No & Total \\
\hline \begin{tabular}{|c|} 
Group \\
1
\end{tabular} & 8 & 42 & 50 & 8 & 42 & 50 & 31 & 19 & 50 & 14 & 36 & 50 \\
\hline $\begin{array}{c}\text { Group } \\
2\end{array}$ & 0 & 50 & 50 & 0 & 50 & 50 & 0 & 50 & 50 & 0 & 50 & 50 \\
\hline Total & 8 & 92 & 100 & 8 & 92 & 100 & 31 & 69 & 100 & 14 & 86 & 100 \\
\hline
\end{tabular}


Physical parameters viz. the body mass index, waist hip ratio, systolic blood pressure and diastolic blood pressure (Table 3) and chemical parameters viz. fasting blood sugar, total cholesterol, triglyceride, HDL, LDL and VLDL were analysed in both groups (Table 4 ).

Mean Body Mass Index was $21.25(+3.04)$ in Group 1 and $20.65(+2.63)$ in Group 2. There is no significant increase in BMI between the groups $(\mathrm{P}=0.28)$. 20 subjects are under weight (BMI < 18.5), whereas 8 subjects are overweight. 6 out of the 8 overweight subjects belonged to the Group 1 and 11 out of 20 underweight subjects were also belonged to Group 1.

There is significant alteration between the groups in the case of waist to hip ratio ( $\mathrm{P}=0.011$ ) even though the waist to hip ratio is only slightly elevated in the Group $1(0.8178+$ $0.06)$ as compared to Group $2(0.8146+0.04)$.

Mean systolic BP of the Group 1 is $119.04(+10.84)$ $\mathrm{mmHg}$ and that of Group 2 is $115.28(+8.53) \mathrm{mmHg}$. No significant change $(\mathrm{P}=0.057)$. Diastolic $\mathrm{BP}$ is also slightly elevated in Group $1(73.52+11.41 \mathrm{mmHg})$ compared to Group $2(70.28+9.50 \mathrm{mmHg})$ but no significant change $(\mathrm{P}=$ 0.244). 4 subjects have high systolic BP (>140 $\mathrm{mmHg}$ ) and 9 subjects have high diastolic BP (> $90 \mathrm{mmHg}$ ). $10 \%$ of the subjects were having hypertension and $9 \%$ of these subjects belong to Group 1.

\begin{tabular}{|c|c|c|c|}
\hline & Group 1 & Group 2 & Significance \\
\hline $\begin{array}{c}\text { Body Mass } \\
\text { Index(BMI) }\end{array}$ & $21.25(+3.04)$ & $20.65(+2.63)$ & $\mathrm{P}=0.289$ \\
\hline $\begin{array}{c}\text { Waist to Hip } \\
\text { Ratio }\end{array}$ & $0.8178(+0.06)$ & $0.8146(+0.04)$ & $\mathrm{P}=0.011$ \\
\hline Systolic BP & $119.04(+10.84)$ & $115.28(+8.53)$ & $\mathrm{P}=0.462$ \\
\hline Diastolic BP & $73.52(+11.41)$ & $70.28(+9.50)$ & $\mathrm{P}=0.244$ \\
\hline \multicolumn{4}{|c|}{ Table 3. Mean Values of Physical Parameters of Study } \\
Subjects \\
\hline
\end{tabular}

Mean Fasting Blood Sugar of the Group 1 was $87.82+$ $12.66 \mathrm{mg} / \mathrm{dL}$ and that of Group 2 is $82.10+11.03 \mathrm{mg} / \mathrm{dL}$. There is a significant change in the blood sugar level between the groups $(\mathrm{P}=0.018)$. 2 subjects have impaired glucose tolerance and both of them belonged to the Group 1.

Mean Total Cholesterol of Group 1 is $184.98+37.79$ $\mathrm{mg} / \mathrm{dL}$ and that of Group 2 is $170.14+35.74 \mathrm{mg} / \mathrm{dL}$. A significant difference in cholesterol level was present between the groups $(\mathrm{P}=0.046) .21$ subjects have above normal level of total cholesterol. Among these 14 subjects belong to the Group 1.

Mean triglyceride level of Group 1 is $87.44+34.89 \mathrm{mg} / \mathrm{dL}$ and Group 2 is $84.36+34.20 \mathrm{mg} / \mathrm{dL}$. There is no significant change in triglyceride level among the groups $(P=0.657)$. Three subjects have higher level of triglycerides than normal value. Out of these two cases belong to Group 1 and the remaining one belongs to Group 2.

HDL cholesterol level also does not show any significant difference between groups $(\mathrm{P}=0.237)$. It is $39.58+13.96$ $\mathrm{mg} / \mathrm{dL}$ and $36.38+12.9 \mathrm{mg} / \mathrm{dL}$ in Group 1 and Group 2 respectively.

LDL cholesterol shows significant difference among the groups. Mean LDL cholesterol level of Group 1 is $129.34+$ $26.78 \mathrm{mg} / \mathrm{dL}$ and of Group 2 is $116.80+23.88 \mathrm{mg} / \mathrm{dL}(\mathrm{P}=$ 0.015). 11 subjects have above normal $(60-150 \mathrm{mg} / \mathrm{dL})$ level. Among these 10 subjects belong to Group 1 and the remaining one belongs to Group 2.

\begin{tabular}{|c|c|c|c|}
\hline Chemical Parameter & Group 1 & Group 2 & Significance \\
\hline $\begin{array}{l}\text { Fasting Blood Glucose } \\
\text { (mg/dL) }\end{array}$ & $\begin{array}{c}87.82+ \\
12.66\end{array}$ & $\begin{array}{c}82.10+ \\
11.03\end{array}$ & $P=0.018$ \\
\hline $\begin{array}{l}\text { Total Cholesterol } \\
(\mathrm{mg} / \mathrm{dL})\end{array}$ & $\begin{array}{c}184.98+ \\
37.79\end{array}$ & $\begin{array}{c}170.14+ \\
35.74\end{array}$ & $P=0.046$ \\
\hline $\begin{array}{c}\text { Triglycerides } \\
(\mathrm{mg} / \mathrm{dL})\end{array}$ & $\begin{array}{c}87.44+ \\
34.89\end{array}$ & $\begin{array}{c}84.36+ \\
34.20\end{array}$ & $P=0.468$ \\
\hline HDL (mg/dL) & $\begin{array}{c}39.58+ \\
13.96 \\
\end{array}$ & $\begin{array}{c}36.38+ \\
12.89 \\
\end{array}$ & $\mathrm{P}=0.237$ \\
\hline $\mathrm{LDL}(\mathrm{mg} / \mathrm{dL})$ & $\begin{array}{c}129.34+ \\
26.78)\end{array}$ & $\begin{array}{c}116.80+ \\
23.88\end{array}$ & $P=0.015$ \\
\hline VLDL (mg/dL) & $17.42+6.92$ & $\begin{array}{c}16.94+ \\
6.81\end{array}$ & $\mathrm{P}=0.475$ \\
\hline \multicolumn{4}{|c|}{$\begin{array}{c}\text { Table 4. The Mean Values of Chemical Parameters } \\
\text { of Study Subjects }\end{array}$} \\
\hline
\end{tabular}

\section{DISCUSSION}

Non-communicable chronic diseases viz. diabetes mellitus, obesity, hypertension, cardiovascular diseases are assuming importance among the adult population in both developed and developing countries. Hypertension, cardiovascular diseases, diabetes and obesity are closely interrelated. Among these, diabetes mellitus, hypertension, hypercholesterolemia etc. have strong hereditary component.

In these circumstances, a comparative study was done in which diabetes mellitus, hypertension, blood sugar, obesity, and lipid profile were studied among young adults in the age group of 18 to 25 years. 50 subjects with family history of diabetes or hypertension (Group 1) and 50 subjects without family history of diabetes or hypertension (Group 2) were included in the study.

Physical parameters viz. the Body Mass Index, Waist Hip ratio, blood pressure (Systolic and diastolic) were elevated in the group 1, but not in a significant manner except waist hip ratio. $8 \%$ of the subjects were overweight, $6 \%$ out of the $8 \%$ over weight subjects belonged to the Group 1 (12\% among the group). $10 \%$ of the subjects were having hypertension and interestingly $9 \%$ of these subjects belong to Group 1 (18 $\%$ among the group).

Chemical parameters were also elevated in the group 1 , compared to group 2. Triglyceride, HDL and VLDL were raised insignificantly. Fasting blood sugar, total cholesterol and LDL cholesterol were elevated in group 1 significantly. 2 $\%$ of subjects have impaired glucose tolerance and all of them belonged to the Group 1 ( $4 \%$ among the group). $21 \%$ subjects have above normal level of total cholesterol. Among these $14 \%$ belongs to the Group 1 (28 \% among the group). $11 \%$ subjects have elevated level of LDL cholesterol. Among these $10 \%$ belong to Group 1 ( $20 \%$ among the group).

Obesity, especially central adiposity is a risk factor for Non-Insulin Dependent Diabetes Mellitus (NIDDM), and the risk is related to both duration and degree of obesity. The risk is apparent with increasing level of BMI, adult weight gain and waist to hip ratio.[16]

Diabetes mellitus have a strong family tendency. Chance of type 1 diabetes in siblings and offspring are 20 times that of general population.[17-19] Cumulative risk of diabetes in siblings of index case with no diabetic parents, one diabetic parent and two diabetic parents are 14\%, 29.2\% and 41.9\% respectively.[9,20] 
It is a well-established fact that a persistently high cholesterol level can almost certainly can precipitate a cardiac event. Risk factors for coronary artery disease are elevated cholesterol level (above $200 \mathrm{mg} / \mathrm{dL}$ ), elevated LDL cholesterol level (Above 130-160 mg/dL), lower levels of HDL cholesterol, elevated Lipoprotein (a) (Above $30 \mathrm{mg} / \mathrm{dL}$ ), cigarette smoking, hypertension, diabetes mellitus, elevated levels of homocysteine (above $15 \mathrm{micromol} / \mathrm{L}$ ), sedentary life style and obesity.[21]

Family studies have shown that children of two normotensive parents have 3\% possibility of developing hypertension, whereas this possibility is $45 \%$ in children of two hypertensive parents. Higher blood pressure levels are seen in black communities than in other ethnic groups.

Central obesity indicated by increased waist to hip ratio has been positively correlated with high blood pressure.[3,22] The prevalence of hypertension is markedly increased in patients with non-insulin dependent diabetes (NIDDM) and also in people with lesser degrees of glucose intolerance.[23]

Gaziano et al.,[24] reported that "the ratio of triglycerides to HDL was a strong predictor of myocardial infarction". An increased plasma concentration of Triglycerides is associated with an increased incidence of coronary artery disease (CAD).[25]

In individuals with type 2 diabetes, metabolic syndrome and the combined dyslipidaemia, cardiovascular risk is increased by a clustering of risk factors such as abdominal obesity, impaired fasting glucose, increased blood pressure, low HDL-cholesterol, increased triglycerides (TGs) and an increase in small, dense LDL particles. The current increase in the incidence of type 2 diabetes in the population perhaps poses the most urgent cardiovascular risk. [26-28]

In the present study risk factors for cardiovascular diseases are generally elevated in the children of parents having diabetes or hypertension, compared to the children of parents not having diabetes or hypertension. In the high risk group, fasting blood sugar, total cholesterol and LDL cholesterol levels are elevated significantly.

Increased total cholesterol and LDL cholesterol levels are reported in patients than in controls.[29-32] Our study also showed similar findings, there is increased total cholesterol and LDL cholesterol level in group 1 subjects than in group 2 subjects.

Obesity promotes the progression of atherosclerosis by inducing multiple cardiovascular and metabolic derangements such as diabetes, hypertension and dyslipidaemia, all of which have high atherogenic potential. ${ }^{[33,34]}$ Increased waist to hip ratio is independently associated with higher risk for diabetes mellitus and cardiovascular disease.

\section{CONCLUSION}

Waist to hip ratio, fasting blood sugar, total cholesterol and LDL cholesterol were significantly increased in young adults with family history of diabetes or hypertension, compared to others without family history of diabetes or hypertension.

This necessitates blood investigations in the younger age group and further follow up study to identify the risk of dyslipidaemia, diabetes mellitus, obesity and development of cardiovascular diseases in our population.

\section{REFERENCES}

[1] Hogarth J. Glossary of health care terminology. WHO, Copenhagen, 1978: p. 34-40.

[2] Charland SL, Stanek EJ. Sigmoidal maximal effect modeling of low-density lipoprotein cholesterol concentration and annual incidence of coronary heart disease events in secondary prevention trials. Pharmacotherapy 2014;34(5):452-63.

[3] Hart JT. Hypertension, library of general practitioner series. Churchill Livingstone 1980: p. 206-18.

[4] Fleischer J, Yderstraede K, Gulichsen E, et al. Cardiovascular autonomic neuropathy is associated with macrovascular risk factors in type 2 diabetes: New technology used for routine large-scale screening Udds new insight. J Diabetes Sci Technol 2014;8(4):874-80.

[5] Hellgren MI, Daka B, Jansson PA, et al. Insulin resistance predicts early cardiovascular morbidity in men without diabetes mellitus with effect modification by physical activity Eur J Prev Cardiol 2015;22(7):9409. Epub 2014 May 30.

[6] Pimenta HB, Caldeira AP. Cardiovascular risk factors on the Framingham Risk Score among hypertensive patients attended by family health teams. Cien Saude Colet 2014;19(6):1731-9.

[7] Yudkin JS. Hypertension and coronary artery disease in non-insulin dependent diabetes--cause and effect? Department of Medicine, University College and MiddLesex School of Medicine, Archway Wing, Whittington Hospital, London, United Kingdom. J Am Soc Nephrol 1992;3(4):S126-S34.

[8] Bamba V. Update on screening, etiology and treatment of dyslipidemia in children. J Clin Endocrinol Metab 2014;99(9):3093-102. Epub 2014 May 21.

[9] Kronenberg F, Steinmetz A, Kostner GM, et al. Lipoprotein (a) in health and disease. (Institute of Medical Biology and Human Genetics, University of Innsbruck, Austria). Crit Rev Clin Lab Sci 1996;33(6):495-543.

[10] Alabakovska SB, Labudovic DD, Tosheska KN, et al. Low density lipoprotein subclass distribution in children with diabetes mellitus. Bratisl Lek Listy 2008;109(4):155-9.

[11] Naito HK, David JA. Laboratory considerations: determination of cholesterol, triglyceride, phospholipids and other lipids in blood and tissues. Lab Res Methods Biol Med 1984;10:1-76.

[12] Hainline A, Karon J, Lippel K. Manual of Laboratory operations. In: Lipid research clinics program. Lipid and lipoprotein analysis. $2^{\text {nd }}$ edn. Bethesda, MD: U.S Dept. of Health and Human Services 1982;89:214-21.

[13] Myers GL, Cooper GR, Winn CL, et al. The centers for Disease control, National Heart, Lung and Blood Institute Lipid Standardization Programme. An approach to accurate and precise lipid measurements. Clin Lab Med 1989;9(1):105-35.

[14] Nauk M, Warnick GR, Rifai N. Methods for measurement of LDL - cholesterol: a critical assessment of direct measurement by homogenous assays versus calculation. Clin Chem 2002;48(2):23654 . 
[15] Mclabe ERB. Disorders of glycerol metabolism. In: Scriver CR, Beudet AL, Sly WS, et al. eds. The metabolic and molecular basis of inherited diseases. New York: McGraw-Hill 1995; 7:1631-52.

[16] Kuwahara K, Uehara A, Kurotani K, et al. Association of cardiorespiratory fitness and overweight with risk of type 2 diabetes in Japanese Men. PLoS One 2014;9(6):e98508.

[17] Gavin JR III, Alberti KGMM, Davidson MB, et al. Report of the expert committee on the diagnosis and classification of diabetes mellitus. Diabetes Care 1997;20(7):1183-97.

[18] Allen C, Palta M, D'Alessio DJ. Risk of diabetes in siblings and other relatives of IDDM subjects. Diabetes 1991;40(7):831-6.

[19] Warram JH, Martin BC, Krolewski AS. Risk of IDDM in children of diabetic mothers decreases with increasing maternal age at pregnancy. Diabetes 1991;40(12):1679-84.

[20] Karter AJ, Rowell SE, Ackerson LM, et al. Excess maternal transmission of type 2 diabetes. The Northern California Kaiser Permanente Diabetes Registry. Diabetes Care 1999;22(6):938-43.

[21] Wilson PW, D'Agostino RB, Levy D, et al. Prediction of coronary heart disease using risk factor categories. Circulation 1998;97(18):1837-47.

[22] Stamler R, Stamler J, RiedLinger WF, et al. Weight and blood pressure. Findings in hypertension screening of 1 million Americans. JAMA 1978;240(15):1607-10.

[23] Jayasinghe R, Craig IH, Mohan RK. Lipoprotein (A) in clinical practice. J Pak Med Assoc 2014;64(4):447-50.

[24] Gaziano JM, Hennekens CH, O’Donnell CJ, et al. Fasting triglycerides, high-density lipoprotein and risk of myocardial infarction. Circulation 1997;96(8):2520-5.

[25] Hokanson JE, Austin MA. Plasma triglyceride level is a risk factor to cardiovascular disease independent of high-density lipoprotein cholesterol level: a metaanalysis of population based prospective studies. J Cardiovasc Risk 1996;3(2):213-9.
[26] Dobia'šva' M. Atherogenic index of plasma [log (Triglycerides/HDL-Cholesterol)]: theoretical and practical implications. Clinical Chemistry 2004;50(7):1113-5.

[27] Gilling L, Suwattee P, DeSouza C, et al. Effects of the thiazolidinediones on cardiovascular risk factors. Am J Cardiovasc Drugs 2002;2(3):149-56.

[28] Tan MH, Johns D, Glazer NB. Pioglitazone reduces atherogenic index of plasma in patients with type 2 diabetes. Clin Chem 2004;50(7):1184-8.

[29] Enas EA, Yusuf S, Mehta JL. Prevalence of coronary artery disease in Asian Indians. Am J Cardiol 1992;70(9):945-9.

[30] Tselepis AD, Elisaf M, Goudevenos J, et al. Lipid profile in patients with microvascular angina. Eur J Clin Invest 1996;26(12):1150-5.

[31] Bolibar I, Thompson SG, Von Eckardstein A, et al. Dose-response relationship of serum lipid measurement with the extent of coronary stenosis. Strong, independent and comprehensive, ECAT Angina Pectoris Study Group. Arterioscler Thromb Vas Biol 1995;15(18):1035-42.

[32] Miwa K, Nakagawa K. Risk factors that discriminate 'high risk' from 'low risk' Japanese patients with coronary artery disease. Jap Cir J 2000;64(11):825-30.

[33] Satoh N, Naruse M, Usui T, et al. Leptin-to-Adiponectin ratio as a potential atherogenic index in obese type 2 diabetic patients. Diabetes Care 2004;27(10):2488-90.

[34] Matsuzawa Y, Funahashi T, Nakamura T. Molecular mechanism of metabolic syndrome $\mathrm{x}$ : contribution of adipocytokines adipocyte-derived bioactive substances. Ann N Y Acad Sci 1999;892(1):146-54. 